\title{
Management of a Fractured Anterior Tooth by Reattachment using Fiber-reinforced Post
}

\author{
${ }^{1}$ Rinsu N Alexander, ${ }^{2} \mathrm{~K}$ Radhakrishnan Nair, ${ }^{3}$ Praveena Geetha, ${ }^{4}$ Nino John, ${ }^{5}$ Aparna Raj, ${ }^{6}$ Meenu M Kumar
}

\begin{abstract}
Reattachment is an effective, economical, and conservative procedure to restore the natural shape, contour, translucency, surface texture, occlusal alignment, and color of the fractured tooth that results in positive emotional and social response in a patient. This case report details the multidisciplinary management of a fractured central incisor with fracture line extending subgingivally in the palatal region. Access opening was done through the fractured segment of 21 and it was detached and stored in saline. After completion of endodontic therapy, crown lengthening procedure was done. Fiber post was placed for added reinforcement and the fragment reattached. A new trauma occurred after 4 months, but the reattached fragment did not get detached.
\end{abstract}

Keywords: Crown lengthening, Crown-root fracture, Fiber post, Reattachment.

How to cite this article:Alexander RN, Nair KR, Geetha P, John N, Raj A, Kumar MM. Management of a Fractured Anterior Tooth by Reattachment using Fiber-reinforced Post. Cons Dent Endod J 2017;2(2):56-59.

Source of support: Nil

Conflict of interest: None

\section{INTRODUCTION}

Crown-root fractures are more complex to treat as the fracture involves the root also. Incidence of tooth fractures is about $5 \%$ and among them, fractures involving root constitute less than 0.5 to $7 \% .^{1}$ As in most traumatic dental injuries, the maxillary central incisor region is most often affected. This type of injury damages not only the dentin, cementum, and tooth pulp, but also the periodontal ligament. ${ }^{2}$ Clinically, the displacement of the coronal fracture segment is minimal as fractured segments are held together by the underlying periodontal

\footnotetext{
${ }^{1,5,6}$ Postgraduate Student, ${ }^{2}$ Professor and Head, ${ }^{3}$ Professor ${ }^{4}$ Specialist Pedodontist

1-3,5,6 Department of Conservative Dentistry and Endodontics Azeezia College of Dental Sciences \& Research, Kollam Kerala, India

${ }^{4}$ Department of Pedodontics, Ministry of Health, Doha, Qatar

Corresponding Author: Rinsu N Alexander, Postgraduate Student, Department of Conservative Dentistry and Endodontics Azeezia College of Dental Sciences \& Research, Kollam, Kerala India, Phone: +919995188036, e-mail: rinsunancy@yahoo.com
}

ligament. ${ }^{1}$ Endodontic treatment and restoration are more problematic when fracture extends subgingivally because of the lack of coronal ferrule and compromised biological width. Treatment options of a subgingival fracture include orthodontic or surgical extrusions, gingivectomy and osteotomy, and intentional replantation. ${ }^{3}$

The development of adhesive dentistry allowed dentists to reattach the patient's own tooth fragment to restore the fractured tooth. After elevation of fracture plane to a supragingival level, reattachment could be easily carried out. Reattachment of fractured tooth segment offers a conservative, esthetic, and cost-effective restorative option and maintains the tooth's original anatomic form, color, and surface texture. The prognosis of the reattached tooth would also depend on the adaptation, contour, and surface finishing of the fragment margins. If stringent plaque control measures are followed, minimal invasion of biologic width will not induce chronic inflammation. ${ }^{4}$

Biological changes in teeth following endodontic treatment leading to reduced hardness and resistance to shearing have been reported. ${ }^{5}$ It has been stated that fiber-reinforced post that is bonded into the root canal of the incisor provides increased retention of the crown's fractured segment and is less subject to root fracture due to a combination of adhesive and elastic properties. ${ }^{6}$

Each case of tooth fracture calls for an individualized treatment plan that addresses the developmental, esthetic, and emotional demands of the patient. This case report details a multidisciplinary management of a fractured central incisor with fracture line extending subgingivally in the palatal region.

\section{CASE REPORT}

A male patient, aged 23, presented with a complaint of fractured maxillary left anterior tooth (21) due to being hit by a football the previous evening. He reported to the casualty on the same day due to pain in the tooth. Upper lip laceration was sutured and painkillers were prescribed. The next day morning, he reported to the outpatient department of Conservative Dentistry and Endodontics. On examination, 21 was found to be fractured. Fracture line was visible labially, but extended subgingivally in the palatal region. There was bleeding along the fracture line. Tooth was tender on percussion. 


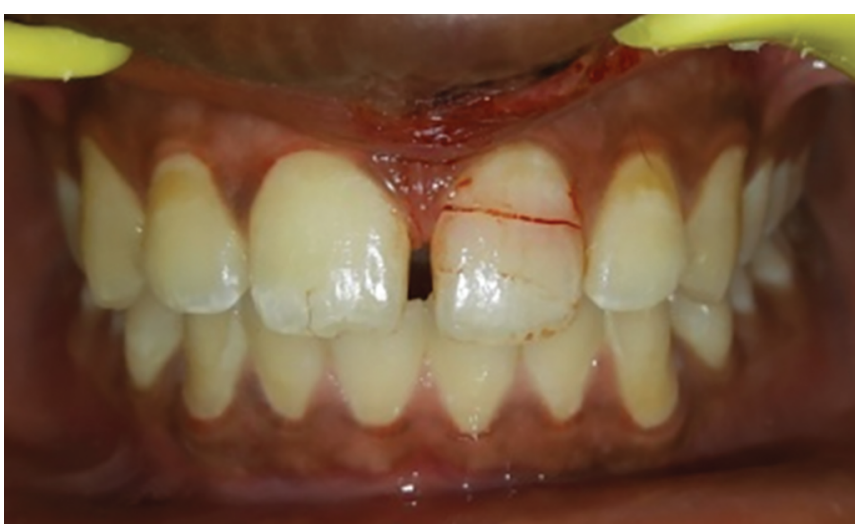

Fig. 1: Preoperative photograph

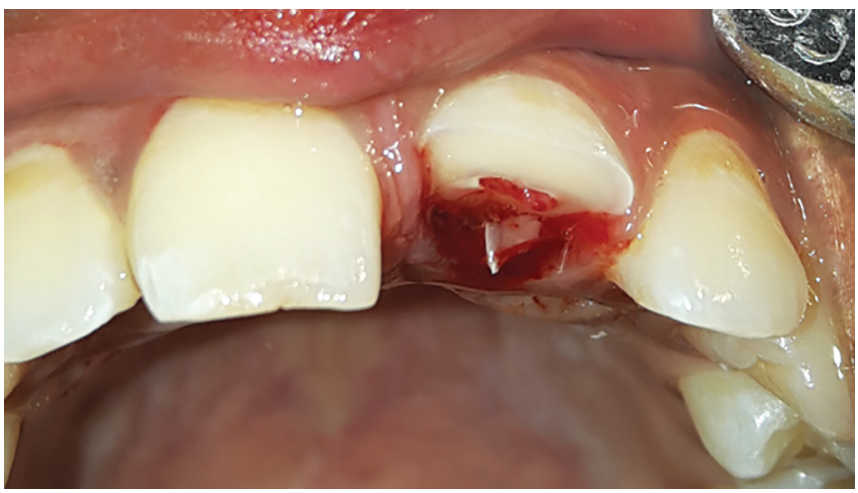

Fig. 3: After fractured segment detachment

The fractured segment was moderately mobile and remained attached to the rest of the tooth (Fig. 1).

Intraoral periapical radiograph revealed a fracture line extending $2 \mathrm{~mm}$ above the cementoenamel junction and another extending horizontally along the junction of gingival and middle third (Fig. 2). The case was diagnosed to be a complicated oblique fracture of 21 . Fracture lines were found to extend horizontally along the junction of gingival and middle thirds labially and subgingivally in the palatal region.

The treatment plan was to initiate endodontic therapy through the fractured segment and reattachment of the coronal segment after completion of endodontic therapy. Root canal therapy was initiated immediately under local anesthesia. After stabilizing with finger pressure, access opening was done through the fractured segment. Then, it was detached and preserved in saline to prevent dehydration and discoloration of tooth fragment (Fig. 3).

The pulp was extirpated and working length radiograph was taken. Cleaning, shaping, and obturation were done in a single visit in relation to 21 . Laser gingivectomy was done in the palatal aspect of 21 to expose the margin (Fig. 4). The detached segment was reattached using resin cement, and gutta-percha was removed using heated hand plugger until an apical $5 \mathrm{~mm}$ of gutta-percha was

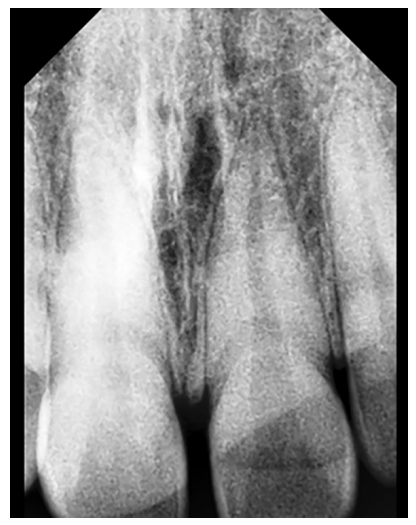

Fig. 2: Preoperative radiograph

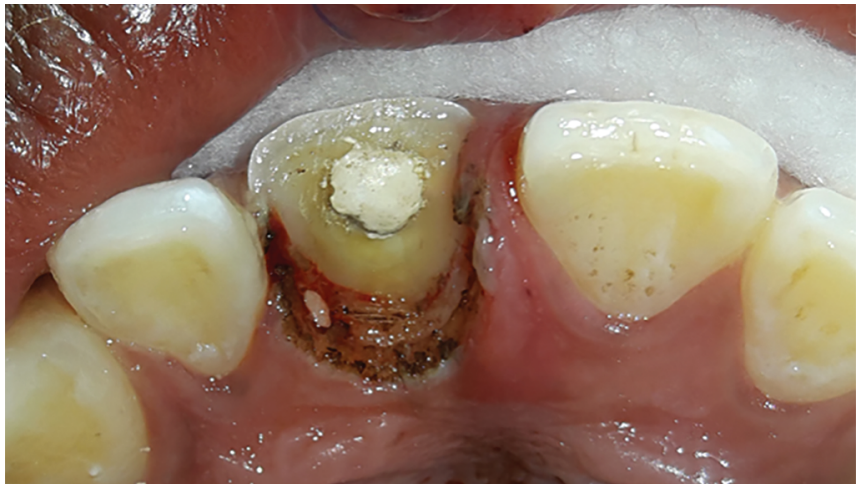

Fig. 4: After laser gingivectomy

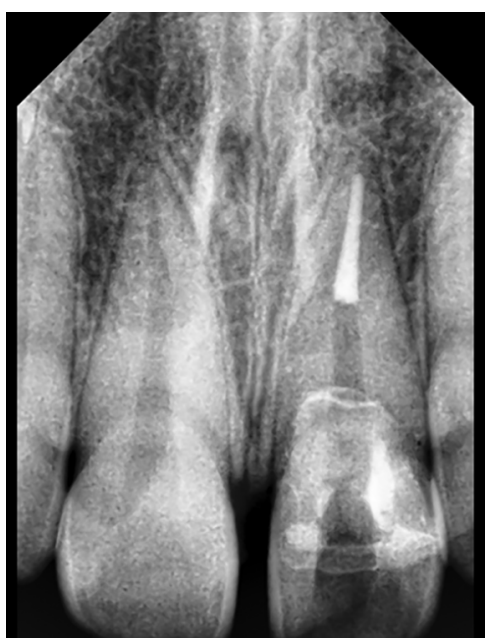

Fig. 5: Post space preparation

retained. Post space was prepared up to Peeso reamer No. 3 (Fig. 5).

Fiber post (Tenax, Coltene) No. 13 was selected, inserted through the post space, and luted using resin cement. Occlusion was evaluated. A check radiograph was recorded to confirm apposition of the two tooth portions (Fig. 6). A groove was prepared along the fracture line labially and restored with composite resin of appropriate shade to conceal the fracture line (Fig. 7).

Postoperative period was uneventful except for a new trauma after 4 months. On clinical examination, slight 


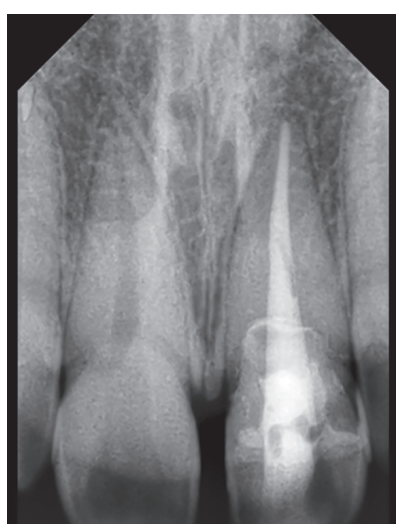

Fig. 6: Fiber post luted

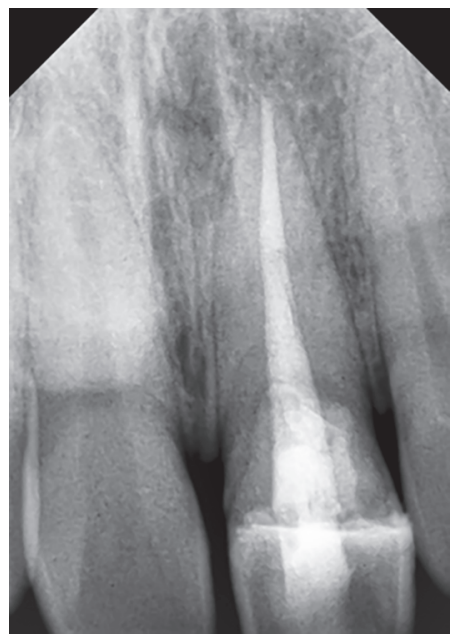

Fig. 8: Review radiograph-12 months

mobility of 21 was noted. Radiographic examination showed no relevant findings. A composite rerestoration along the fracture margin was done and occlusion evaluated. The patient was given postoperative instructions. During follow-up examination at 12 months, the tooth was asymptomatic with no mobility, no tenderness, and no attachment loss (Fig. 8).

\section{DISCUSSION}

This was a case of complicated crown-root fracture, which involves enamel, dentin, pulp, and cementum, extending below the gingival margin palatally. As the fractured coronal segment of the tooth was intact, fragment reattachment was considered. The main objective of the treatment consists of exposing the fracture margin to a supragingival level, so that clinical restoration procedures can be conducted without contamination with blood and saliva. ${ }^{7-9}$

As anterior teeth encounter more of shear forces, reinforcement of the fractured segment with fiber post was preferred. Access opening was done through the fractured segment before detaching it so as to obtain a uniform opening in both fragments, which will later help in for

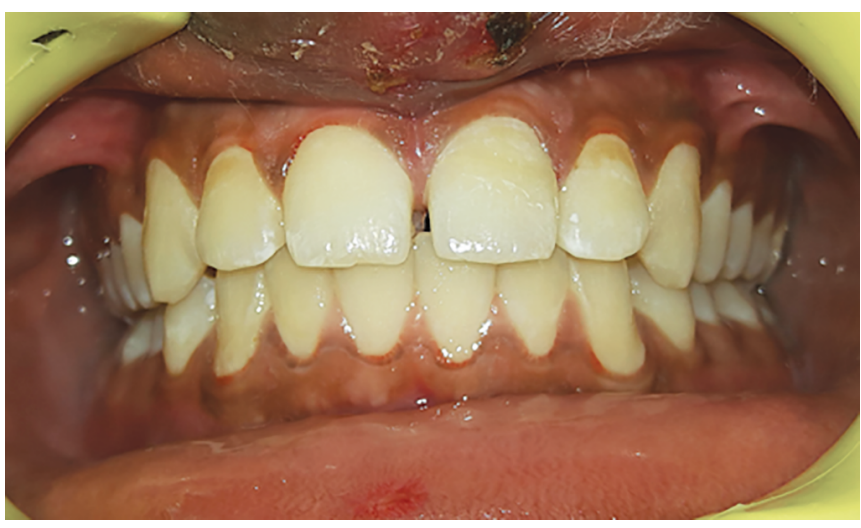

Fig. 7: Postoperative photograph

an easier post placement. Palatal margin was exposed by laser gingivectomy using diode laser to visualize the margins. Once the margins were exposed, tooth fragment was reattached by using resin cement.

When endodontic therapy is required, the space provided by the pulp chamber may be used as an inner reinforcement, thus avoiding any excessive preparation of the fractured tooth. ${ }^{10}$ Hence, in this case, the pulp chamber acted as the reinforcement factor. Additional reinforcement was given by the use of fiber post. This type of fracture is found to be the bleakest because of the loss of the coronal fragment stability and pulpal vitality. The coronal fragment did not get detached by second trauma probably due to the additional reinforcement provided by the fiber post.

Reinforcing with tooth-colored fiber posts has several advantages. They are more esthetic, bonded to tooth tissue, modulus of elasticity is similar to that of dentin (18 GPa), and have less chances of fracture. Traditionally cast metal post and core were used for fracture reattachment. The newer variety of nonmetallic posts is made of either ceramic or fiber-reinforced materials like carbon, quartz, or glass in an epoxy matrix. By using glass fiber post with composite core and with recent advances in adhesive techniques and materials, one can create a mono-block, a multilayered structure with no inherent weak interlayer interfaces. Therefore, the integrity of the final endodontic-restorative continuum mono-block approaches that of the original healthy tooth itself. ${ }^{11} \mathrm{An}$ additional use of fiber posts is that they help to distribute the stress uniformly to the remaining radicular dentin.

The possible postoperative complications include discoloration of the reattached fragment and fracture to labial horizontal forces with new trauma. Hence, regular follow-up is necessary.

\section{CONCLUSION}

For traumatized patients with broken teeth, pain relief and an esthetic immediate restoration are the treatment goals. Crown-root fracture is a difficult clinical situation 
to be managed. Reattachment proved to be a successful technique in this case for restoring esthetics and function, considering the age and occlusion of the patient. Insertion of flexible fiber post reinforces the tooth against functional forces. If meticulous plaque control measures are followed, minimal invasion of biologic width will not induce a chronic inflammation.

\section{REFERENCES}

1. Suresh Chandra, B.; Gopikrishna, V.; editors. Grossman's endodontic practice. 13th ed. India: Wolters Kluwer Health; 2014.

2. Welbury R, Kinirons MJ, Day P, Humphreys K, Gregg TA. Outcomes for root-fractured permanent incisors: a retrospective study. Pediatr Dent 2002 Mar-Apr;24(2):98-102.

3. Fidel SR, Fidel-Junior RA, Sassone LM, Murad CF, Fidel RA. Clinical management of a complicated crown-root fracture: a case report. Braz Dent J 2011;22(3):258-262.

4. Frese C, Wolff D, Staehle HJ. Proximal box elevation with resin composite and the dogma of biological width: clinical
R2-technique and critical review. Oper Dent 2014 JanFeb;39(1):22-31.

5. Johnson JK, Schwartz NL, Blackwell RT. Evaluation and restoration of endodontically treated posterior teeth. J Am Dent Assoc 1976 Sep;93(3):597-605.

6. Valceanu AS, Stratul SI. Multidisciplinary approach of complicated crown fractures of both superior central incisors: a case report. Dent Traumatol 2008 Aug;24(4):482-486.

7. Turgut MD, Gönül N, Altay N. Multiple complicated crownroot fracture of a permanent incisor. Dent Traumatol 2004 Oct;20(5):288-292.

8. Olsburgh S, Jacoby T, Krejci I. Crown fractures in the permanent dentition: pulpal and restorative considerations. Dent Traumatol 2002 Jun;18(3):103-115.

9. Caliskan MK, Türkün M, Gomel M. Surgical extrusion of crown-root-fractured teeth: a clinical review. Int Endod J 1999 Mar;32(2):146-151

10. Reis A, Loguercio AD, Kraul A, Matson E. Reattachment of fractured teeth: a review of the literature. Oper Dent 2004 Mar-Apr;29(2):226-233.

11. Tay FR, Pashley DH. Monoblocks in root canals: a hypothetical or tangible goal. J Endod 2007 Apr;33(4):391-398. 